\title{
A slotted circular monopole antenna for wireless applications
}

\author{
Gopal M. Dandime*, Veeresh G. Kasabegoudar \\ Post Graduate Department., Mahatma Basveshwar Education Society's, College of engineering, Ambajogai, India
}

Email address:

gopaldandime@gmail.com (G. M. Dandime), veereshgk2002@rediffmail.com (V. G. Kasabegoudar)

\section{To cite this article:}

Gopal M. Dandime, Veeresh G. Kasabegoudar. A Slotted Circular Monopole Antenna for Wireless Applications. International Journal of Wireless Communications and Mobile Computing. Vol. 2, No. 2, 2014, pp. 30-34. doi: 10.11648/j.wcmc.20140202.12

\begin{abstract}
In this paper, a compact slotted circular monopole antenna with spike shaped slots embedded in it is presented. Also, the proposed antenna has ground length limited to $33 \%$ of substrate length. This ground is provided on the back side of the antenna geometry to excite the antenna by microstrip line feed. A slotted circular patch element will be achieved by subtracting 45 degrees rotated square patch of $12 \mathrm{~mm} \times 12 \mathrm{~mm}$, and then by proper scaling. In this study the geometry is scaled separately by $60 \%, 40 \%, 20 \%$, and finally the resultant is obtained by uniting them. This final geometry offers an ultra wide band operation. The overall size of the antenna is $30 \mathrm{~mm} \times 32.4 \mathrm{~mm} \times 1.6 \mathrm{~mm}$ including finite ground feeding mechanism. The antenna operates in the frequency range from $2.5-15 \mathrm{GHz}$ covering FCC defined UWB band with more than $130 \%$ impedance bandwidth. Stable omni-directional radiation patterns in the desired frequency band have been obtained. Measured data fairly agree with the simulated results.
\end{abstract}

Keywords: Ultra Wideband, Printed Monopole Antenna, Slot Antenna, Defected Ground Structure (DGS)

\section{Introduction}

As we know that in patch antenna's narrow bandwidth is a major disadvantage and current wireless applications demand for wide bandwidth to integrate several applications. Therefore it is necessary to design antenna with compact size, wide bandwidth, and low profile. In the recent years printed monopole antennas are popular due to some advantages like low profile, etched on a dielectric substrate and can provide feature of broadband and multiband. Novel printed monopole antenna presented in [1] has cross slotted shaped slot with tapered shaped microstrip to achieve broadband matching. Planar monopole antennas can be used for UWB applications due to their wideband characteristics [2].

The Ultra Wideband (UWB) refers to the frequency range of 3.1 to $10.6 \mathrm{GHz}$ [3]. As this band is unlicensed by FCC which encourages the designers to go for UWB antennas [1-13]. Microstrip line feed is more suitable to excite a patch antenna as it facilitates proper impedance matching. Hence, these microstrip feeds are preferred for wireless applications and also the similar feed is used in this work. In this paper we propose a printed monopole antenna with operating frequency ranges from $2.8 \mathrm{GHz}$ to $12 \mathrm{GHz}$ which is close to $124 \%$ (impedance bandwidth). There are several bandwidth enhancement techniques used in monopole antennas to achieve such a huge bandwidth. In proposed antenna we have used the slots in circular shaped patch in which square is subtracted and then scaled \& united together. A microstrip feed with dimensions of length equal to $11.9 \mathrm{~mm} \&$ width of $2.9 \mathrm{~mm}$ is used for excitation. In this work, a compact microstrip fed slotted circular patch monopole antenna is presented. Although, the antenna demonstrated in this paper is similar to the geometry presented in [12], has several changes like much smaller dimensions, microstrip feed rather than CPW feed to acheive better gain. Even though the microstrip feed is used, it offers impedance bandwidth similar to [12]. The antenna is simulated using Ansoft's High Frequency Structure Simulator (HFSS) v.13. More details on this geometry are discussed in subsequent sections. Section 2 presents the geometry structure of the proposed antenna. Design and optimization procedure of the proposed antenna is presented in Section 3. Section 4 presents the validation of the fabricated prototype and discussions on the measured results are also presented there. Finally, conclusions of this study are presented in Section 5. 


\section{Antenna Geometry}

Figure 1(a) shows the basic geometry of proposed circular monopole antenna for UWB operation. The antenna is symmetrical with respect to the longitudinal direction. Substrate used for the design is FR4 with dielectric constant of 4.4 , and thickness of $1.6 \mathrm{~mm}$. Finite ground planes, with dimensions of length $\mathrm{L}_{\mathrm{g}}$ and width $\mathrm{W}_{\mathrm{g}}$ are placed symmetrically on either side of the microstrip feed-line. The proposed geometry is fed by the microstrip line. The detailed optimization procedure of the proposed antenna and its optimum dimensions, and characteristics are presented in Section 3. All the parameters of the geometry are indicated in Figure 1 (a) and optimized dimensions are listed in Table 1.

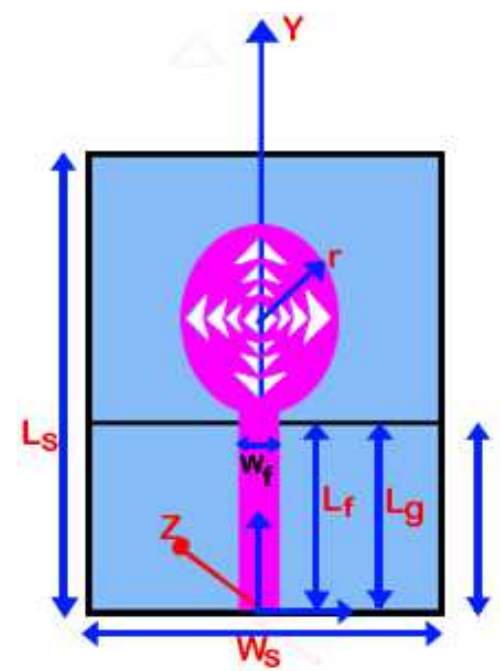

(a) Top view

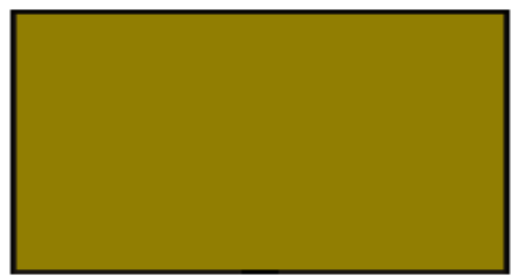

(b) Bottom view (ground)

Figure 1. Geometry of proposed microstrip fed monopole antenna.

Table 1. Optimized dimension of the proposed antenna

\begin{tabular}{lcc}
\hline Geometry Parameter & Notation & Dimensions of geometry in mm \\
\hline Radius of Patch & $r$ & 9.50 \\
Substrate Length & $L_{s}$ & 32.4 \\
Substrate Width & $W_{s}$ & 30.0 \\
Feed Length & $L_{f}$ & 11.9 \\
Feed Width & $W_{f}$ & 2.90 \\
Ground Length & $L_{g}$ & 10.9 \\
\hline
\end{tabular}

\section{Geometry Optimization and Discussions}

In this section parametric study is conducted to optimize the proposed antenna. The key design parameters used for the optimization are radius of circular patch, square slot, ground plane length, and length \& width of the feed. The detailed analysis of these parameters is investigated in the following subsections.

\subsection{Effect of Square Slot and Scaling of Patch Geometry}

As shown in Figure 2, circular patch geometry is subtracted by a square slot of dimensions $12 \mathrm{~mm}$ by $12 \mathrm{~mm} \&$ then whole geometry is scaled to $60 \%, 40 \%$ \& finally $20 \%$ to see scaling effect on the performance of antenna. Return loss characteristics of this study are presented in Figure 3. From Figure 3 it may be noted that the fourth iteration offers wide impedance bandwidth. This is mainly due to the excitation of closely spaced multi resonance which merges and offer wide impedance bandwidth.

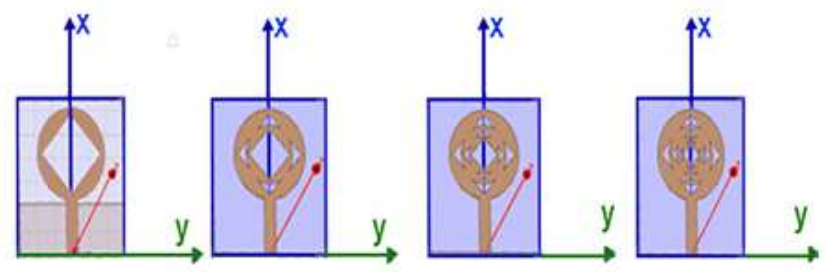

$\begin{array}{llll}\text { (a) } 1^{\text {st }} \text { Iteration } & \text { (b) } 2^{\text {nd }} \text { Iteration } & \text { (c) } 3^{\text {rd }} \text { Iteration } & \text { (d) } 4^{\text {th }} \text { Iteration }\end{array}$

Figure 2. Geometry modification of antenna by scaling process of patch

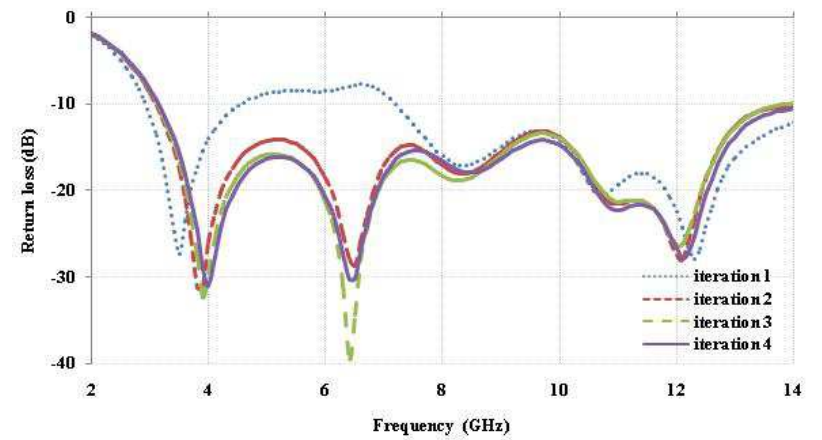

Figure 3. Return loss vs. frequency plot for variation in geometry of patch as indicated in Figure 2.

Table 2. Effect of variation of geometry on bandwidth of proposed antenna

\begin{tabular}{lcccc}
\hline Iteration & $\begin{array}{c}\mathbf{1}^{\text {st }}(\mathbf{N o} \\
\text { Scaling) }\end{array}$ & $\begin{array}{c}\mathbf{2}^{\text {nd }}(\mathbf{6 0} \% \\
\text { Scaling) }\end{array}$ & $\begin{array}{c}\mathbf{3}^{\text {rd }}(\mathbf{4 0 \%} \\
\text { Scaling) }\end{array}$ & $\begin{array}{c}\mathbf{4}^{\text {th }}(\mathbf{2 0 \%} \\
\text { Scaling) }\end{array}$ \\
\hline $\begin{array}{l}\text { Frequency range } \\
(\mathrm{GHz})\end{array}$ & $7.5-15$ & $3-14.8$ & $3-15$ & $3-15$ \\
$\begin{array}{l}\text { Bandwidth (\%) } \\
\begin{array}{l}\text { Positive Gain Freq. } \\
\text { Range (GHz) }\end{array}\end{array}$ & 66.6 & 132.5 & 133.3 & 133.3 \\
\hline
\end{tabular}




\subsection{Effect of Radius \& Ground Dimensions}

To study the effect of circular patch dimensions on the antenna performance, its radius (r) is varied. Initially, the radius of the patch (r) is varied from $6.5 \mathrm{~mm}$ to $12.5 \mathrm{~mm}$ in steps of $1 \mathrm{~mm}$ keeping ground dimensions \& feed dimensions constant $\left(\mathrm{L}_{\mathrm{f}}=11.9 \mathrm{~mm}, \mathrm{~W}_{\mathrm{f}}=2.9 \mathrm{~mm}\right)$. From the simulations we found an optimum radius (r) of $9.5 \mathrm{~mm}$. Return loss characteristics of this study are depicted in Figure 4 and calculated bandwidth values are presented in Table 3. From Figure 4, it may be noted that the lower cut-off frequency remains nearly constant whereas upper cut-off frequency varies slightly i.e., bandwidth varies with respect to radius parameter. From Table 3 it is found that the geometry offers the maximum impedance bandwidth of $124 \%$. Also, the defected ground behind the monopole geometries offer a wide impedance bandwidth [14-17], in this work we have included a finite ground of size equal to $\mathrm{L}_{\mathrm{g}} \mathrm{x} \mathrm{W}_{\mathrm{s}}$. Width of the ground is chosen equal to the substrate width and length is chosen such that it covers only feed line of the monopole antenna.

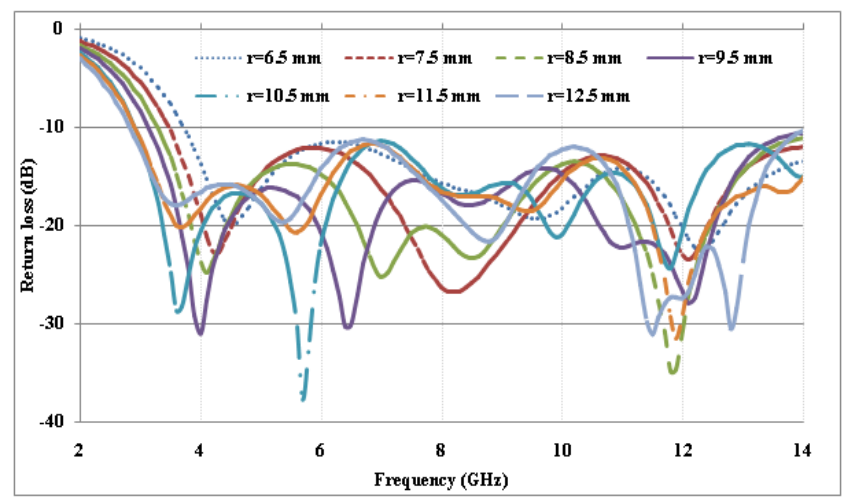

Figure 4. Return loss vs. frequency plot with variable radius of the circular patch ( $r$.

Table 3. Effect of variation of radius of patch on bandwidth of proposed antenna

\begin{tabular}{|c|c|c|c|c|c|c|c|}
\hline $\begin{array}{l}\text { Radius }(r) \\
(\mathrm{mm})\end{array}$ & 6.5 & 7.5 & 8.5 & 9.5 & 10.5 & 11.5 & 12.5 \\
\hline $\begin{array}{l}\text { Frequency } \\
\text { Range } \\
\text { (GHz) }\end{array}$ & $3.76-15$ & $\begin{array}{l}3.5- \\
15\end{array}$ & $\begin{array}{l}3.26-1 \\
5\end{array}$ & $\begin{array}{l}3.12-1 \\
5\end{array}$ & $\begin{array}{l}3.22-1 \\
4.56\end{array}$ & $\begin{array}{l}3.21-1 \\
4.72\end{array}$ & $\begin{array}{l}3.72-1 \\
5\end{array}$ \\
\hline $\begin{array}{l}\text { Bandwidth } \\
\text { (\%) }\end{array}$ & 119.8 & 124.3 & 128.5 & 131.2 & 127.5 & 128.3 & 120.5 \\
\hline
\end{tabular}

\subsection{Effect of Length \& Width of Feed Line}

In this investigation, first by keeping feed width constant $\left(\mathrm{W}_{\mathrm{f}}=2.9 \mathrm{~mm}\right)$ the length of feed line was varied from $7.9 \mathrm{~mm}$ to $14.9 \mathrm{~mm}$ in steps of $2 \mathrm{~mm}$ and its effects are presented in Figure 5(a) and Table 4. From Figure 5 (a) it may be noted that the optimized results are obtained for feed length $\mathrm{L}_{\mathrm{f}}=11.9 \mathrm{~mm}$. In the further study, feed length $\mathrm{L}_{\mathrm{f}}=11.9 \mathrm{~mm}$ was kept constant and feed width $\left(\mathrm{W}_{\mathrm{f}}\right)$ was varied from $2.3 \mathrm{~mm}$ to $2.9 \mathrm{~mm}$ in steps of $0.2 \mathrm{~mm}$ The $S_{11}$ characteristics of this study are presented in Figure 6 and Table 5. From this study, optimized value of feed width equal to $2.9 \mathrm{~mm}$ is obtained. It may be noted that these dimension vary the input impedance of the antenna and optimized as explained above to yield maximum impedance bandwidth.

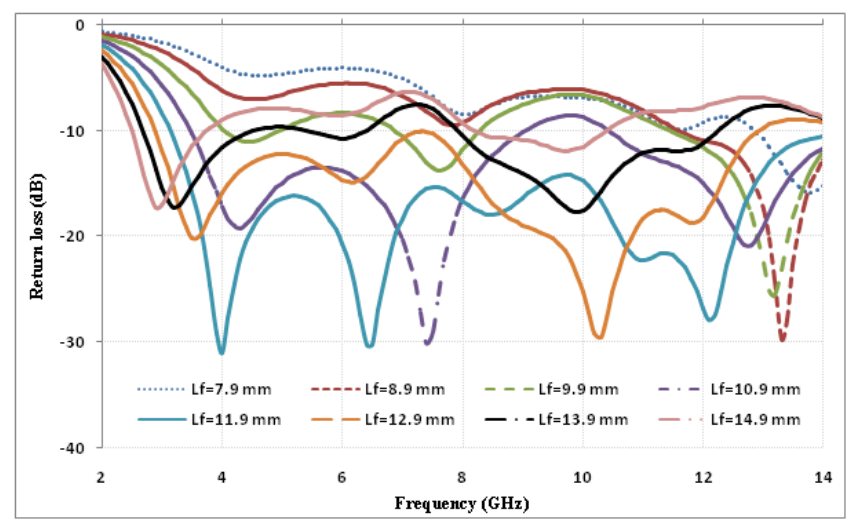

Figure 5. Return loss vs. frequency plot for feed length variation.

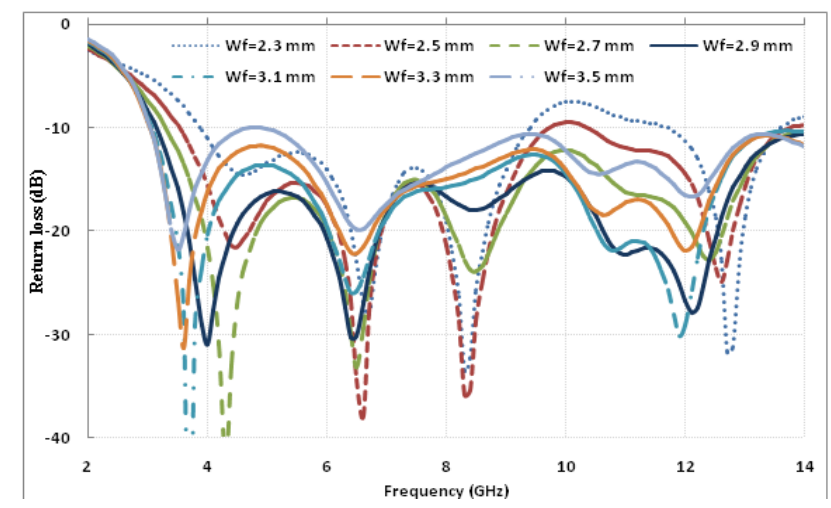

Figure 6. Return loss vs. frequency plot for feed width variation.

Table 4. Effect of feed length on bandwidth of proposed antenna

\begin{tabular}{lllllll}
\hline Feed & 9.9 & 10.9 & 11.9 & 12.9 & 13.9 & 14.9 \\
$\begin{array}{l}\text { Length(mm) } \\
\text { Bandwidth(\%) }\end{array}$ & 66.6 & 88 & 131.25 & 129.11 & 126.53 & 26.087 \\
\hline
\end{tabular}

Table 5. Effect of feed width on bandwidth of proposed antenna

\begin{tabular}{llllllll}
\hline $\begin{array}{l}\text { Feed } \\
\text { Width(mm) }\end{array}$ & 2.3 & 2.5 & 2.7 & 2.9 & 3.1 & 3.3 & 3.5 \\
$\begin{array}{l}\text { Bandwidth } \\
\text { (\%) }\end{array}$ & $\begin{array}{l}83.7 \\
3\end{array}$ & 118.6 & 128.76 & 131.25 & 124.9 & 127.9 & 124.45 \\
\hline
\end{tabular}

\section{Experimental Results and Discussions}

The geometry shown in Figure 1 with its optimized dimensions using HFSS EM software [18] presented in Table 1 was fabricated and tested. The substrate used for the fabrication is the FR4 glass epoxy with dielectric constant of 4.4 , and thickness of $1.6 \mathrm{~mm}$. A photograph of the fabricated prototype is shown in Figure 7. Return loss comparisons of measured and simulated values are compared in Figure 8. The measured results are fairly agreed with the simulated values.

From Figure 8 it may be noted that the proposed antenna is having measured operating frequency range from $4.5 \mathrm{GHz}$ to $12 \mathrm{GHz}$. This corresponds to an impedance bandwidth 
(measured) close to $100 \%$. Radiation patterns of the geometry are presented at various frequencies in the band of operation (Figure 9). These patterns are symmetrical at the start and middle frequencies of the band of operation with nearly omni-directional shape in the H-plane. However, at the end of operating band of frequencies the patterns degrade which could be due complex current distributions at the end of operating frequency band [13].

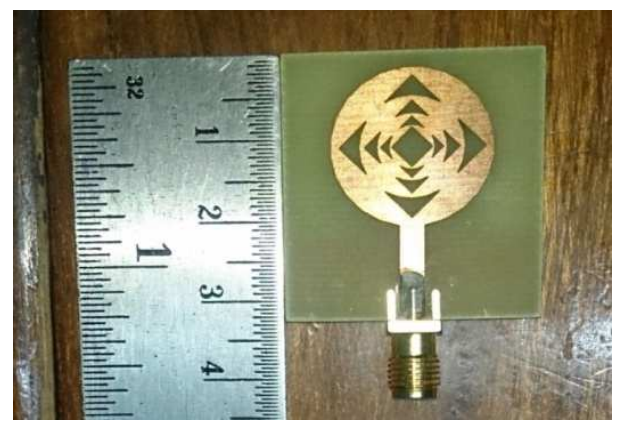

Figure 7. Fabricated prototype of antenna shown in Figure 1.

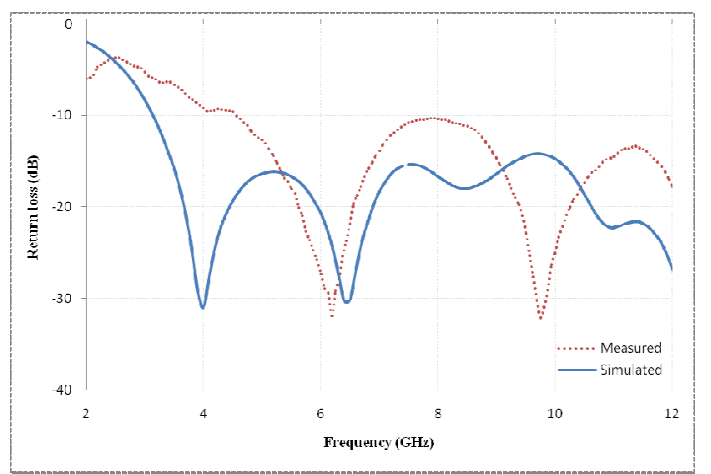

Figure 8. Return loss characteristics comparisons of the antenna geometry shown in Figure 1.

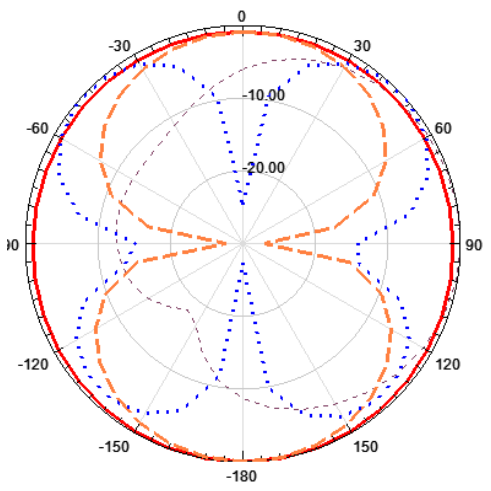

(a) $3.2 \mathrm{GHz}$

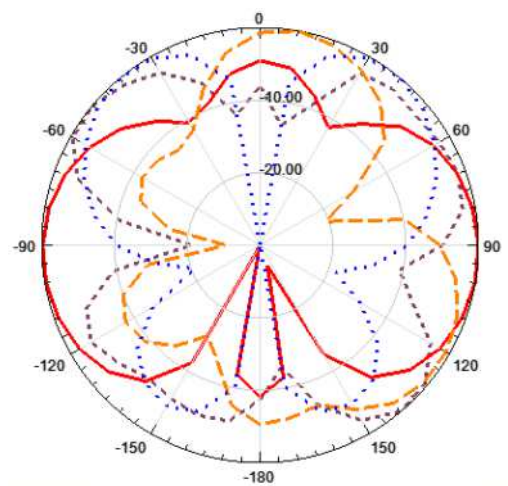

(b) $9.1 \mathrm{GHz}$

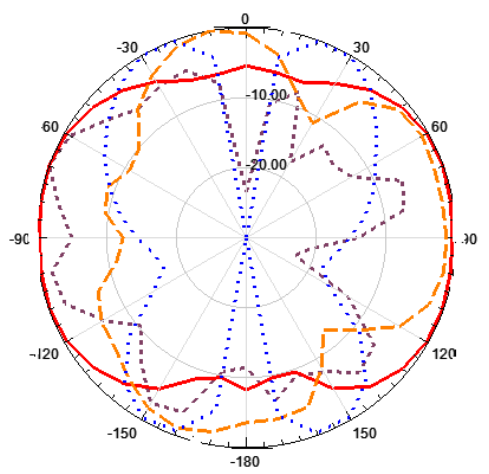

(c) $12 \mathrm{GHz}$

Figure 9. Radiation patterns at various frequencies of the antenna shown in Figure 1. Red (solid): H-Co. Poln.; Orange (Long-Dash): E-Co. Poln.; Blue (Doted): E-Cross Poln.; Brown (Short-Dash): H-Cross Poln.

\section{Conclusions}

A compact circular shaped slotted monopole antenna mounted on rectangular base with finite ground has been presented. Ground geometry was varied \& fixed with optimum size to $33 \%$ to offer wide impedance bandwidth and good gain. Also, by varying feed length $\&$ width a perfect impedance matching can be obtained. The antenna presented here offers an impedance bandwidth of more than $124 \%$ in the frequency range of $2.8 \mathrm{GHz}$ to $12 \mathrm{GHz}$ which essentially covers the FCC defined ultra wideband (UWB) frequency range. Omni-directional radiation patterns were obtained throughout the band of operation. Therefore, the antenna presented here is a suitable for the FCC defined UWB band of operation.

\section{References}

[1] R. S. Kshetrimayum and R. Pillalamarri, "Novel UWB printed monopole antenna with tapered feed lines," Indian Institute of Technology, Guwahati, India 2009.

[2] G. Kumar and K. P. Ray, Broadband Microstrip Antennas, Artech House Boston, London, 2002. 
[3] J. R. Panda and R. S. Kshetrimayum, "An F-shaped printed monopole antenna for dual-band RFID and WLAN applications," Indian Institute of Technology, Guwahati, India 2010 .

[4] First Report and Order, Revision of part 15 of the commission's rule regarding ultra- wideband transmission systems FCC 02-48, Federal Communications Commission, 2002.

[5] W.-J. Liu, Q.-X. Chu, and L.-H. Ye, “A low-profile monopole antenna embedded with a resonant slot," Progress In Electromagnetic Research Letters, vol. 14, pp. 59-67, 2010.

[6] K. C. gupta, R. Gerg, I. Bahl and P. Bhartia, Microstrip Lines and Slotline, Artech House, Boston, London.

[7] R. S. Kshetrimayum, J. R. Panda, and R. Pillalamarri "UWB printed monopole antenna with a notch frequency for coexistence with IEEE 802.11a WLAN devices," Indian Institute of Technology, Guwahati, India, 2009.

[8] Z.-A. Zheng and Q.-X. Chu, "Compact CPW-fed UWB antenna with dual band notched characteristics," Progress In Electromagnetics Research Letters, vol. 11, pp. 83-91, 2009.

[9] N. Kushwaha and R. Kumar, "An UWB fractal antenna with defected ground structure and swastika shape electromagnetic band gap," Progress In Electromagnetics Research B, vol. 52, pp. 383-403, 2013.

[10] S. Sadat, M. Fardis, F. Geran, and G. Dadashzadeh, "A compact microstrip square-ring slot atenna for UWB applications," Progress In Electromagnetics Research, vol. 67, pp. 173-179, 2007.
[11] C.A. Balanis, Antenna Theory Analysis \& Design, 3rd Edition, John Wiley \& Sons, New York, 2011.

[12] R. Kumar and K. K. Sawant, "Design of CPW-fed fourth iterative UWB fractal antenna," International Journal of Microwave \& Optical Technology, vol. 5, no. 6, pp. 320-327, 2010.

[13] M. K. Kulkarni and V. G. Kasabegoudar, A CPW-fed triangular monopole antenna with staircase ground for UWB applications," Int. J. Wireless Communications and Mobile Computing, vol. 1, no. 4, pp. 129-135, 2013.

[14] Y.S. Li, W.X. Li and Q.B. Ye, “ Compact reconfigurable UWB antenna integrated with stepped impedance stub loaded resonators and switches," Progress In Electromagnetics Research, vol. 27, pp. 239-252, 2007

[15] J. K. Ali, A.J. Salim, A.I. Hammoodi and H. Alsaedi, "An Ultra-wideband printed monopole antenna with a fractal based reduced ground plane," Progress In Electromagnetics Research Symposium Proceedings, vol. 19, pp. 613-617, 2012

[16] K. R. Dharani and D. Pavithra, " a simple miniature U-shaped slot antenna for WIMAX applications," International Journal of Advance in Engineering \& Technology, pp. 1256-1262, 2013

[17] R. Ghatak, A. Karmakar, and D.R. Poddar, "A circular shaped sierpinsik carpet fractal UWB monopole antenna with band rejection capability," Progress In Electromagnetics Research, vol. 24, pp. 221-234, 2011.

[18] HFSS13.0 User's Manual, Ansoft Corporation, Pittsburgh. 